\title{
Comparative metabolic responses and adaptive strategies of wheat (Triticum aestivum) to salt and alkali stress
}

\author{
Rui Guo ${ }^{1 * \dagger}$, Zongze Yang ${ }^{2 \dagger}$, Feng Li ${ }^{1}$, Changrong Yan ${ }^{1}$, Xiuli Zhong ${ }^{1}$, Qi Liu' ${ }^{1}$ Xu Xia ${ }^{1}$, Haoru Li ${ }^{1}$ and Long Zhao ${ }^{2}$
}

\begin{abstract}
Background: It is well known that salinization (high-pH) has been considered as a major environmental threat to agricultural systems. The aim of this study was to investigate the differences between salt stress and alkali stress in metabolic profiles and nutrient accumulation of wheat; these parameters were also evaluated to determine the physiological adaptive mechanisms by which wheat tolerates alkali stress.

Results: The harmful effect of alkali stress on the growth and photosynthesis of wheat were stronger than those of salt stress. High-pH of alkali stress induced the most of phosphate and metal ions to precipitate; as a result, the availability of nutrients significantly declined. Under alkali stress, Ca sharply increased in roots, however, it decreased under salt stress. In addition, we detected the 75 metabolites that were different among the treatments according to GC-MS analysis, including organic acids, amino acids, sugars/polyols and others. The metabolic data showed salt stress and alkali stress caused different metabolic shifts; alkali stress has a stronger injurious effect on the distribution and accumulation of metabolites than salt stress. These outcomes correspond to specific detrimental effects of a highly $\mathrm{pH}$ environment.
\end{abstract}

Conclusions: Ca had a significant positive correlation with alkali tolerates, and increasing Ca concentration can immediately trigger SOS Na exclusion system and reduce the Na injury. Salt stress caused metabolic shifts toward gluconeogenesis with increased sugars to avoid osmotic stress; energy in roots and active synthesis in leaves were needed by wheat to develop salt tolerance. Alkali stress (at high $\mathrm{pH}$ ) significantly inhibited photosynthetic rate; thus, sugar production was reduced, N metabolism was limited, amino acid production was reduced, and glycolysis was inhibited.

Keywords: Wheat, Salt stress, Alkali stress, Growth, Photosynthesis, Metal elements, Free ions, Metabolites

\section{Background}

Salinization has been considered as a major environmental threat to agricultural systems; approximately $20 \%$ of arable land and $50 \%$ of irrigated land worldwide have been affected by salinity $[1,2] . \mathrm{K}^{+}, \mathrm{Na}^{+}, \mathrm{Ca}^{2+}, \mathrm{Mg}^{2+}, \mathrm{Cl}^{-}$, $\mathrm{NO}_{3}^{-}, \mathrm{HCO}_{3}^{-}, \mathrm{CO}_{3}^{2-}$, and $\mathrm{SO}_{4}^{2-}$ are predominant ions in natural saline soils. Läuchli and Lüttge confirmed that soil salinization and alkalization occur simultaneously [3]. Thus far, studies have mainly focused on salt stress

\footnotetext{
* Correspondence: guor219@yahoo.com

${ }^{+}$Equal contributors

'Institute of Environment and Sustainable Development in Agriculture (IEDA), Chinese Academy of Agricultural Sciences (CAAS)/Key Laboratory of Dryland Agriculture, Ministry of Agriculture, Beijing 100081, P.R. China

Full list of author information is available at the end of the article
}

$[4,5]$. Although studies on high-pH calcareous soils, alkaline soils, and alkaline salt stress have also conducted, studies on alkali stress have been rarely performed [6-8].

Salt stress induces osmotic stress and ion injury by disrupting ion homeostasis and ion balance in plant cells; alkali stress exhibits the same stress factors but becomes aggravated when combined with high-pH stress [9-12]. A highly alkaline environment in the rhizosphere can reduce mineral element availability by precipitating $\mathrm{Ca}^{2+}, \mathrm{Mg}^{2+}$, and $\mathrm{HPO}_{3}^{-}$; as a result, ion uptake is inhibited and ion homeostasis is disrupted [13, 14]. High $\mathrm{pH}$ can also immediately destroy root membrane structure and strongly affect structural functions, such as break intracellular ion balances [15]. Thus, plants in alkaline soil must cope with physiological drought and ion 
toxicity, maintain intracellular ion balance, and regulate $\mathrm{pH}$ outside roots. Plant responses to alkali stress may involve metabolic pathways, such as ion transport, photosynthesis, osmotic solute accumulation, and hormone synthesis. Metabolomic solutes, such as proline, betaine, polyamine, and polyhydric alcohol, contribute to salt stress tolerance. Metabolomic components may participate in plant alkali tolerance; however, information regarding alkali tolerance-related metabolomic components is limited. A comparative metabolic analysis of plant response to salt and alkali stress will be conducted to determine metabolomic components with high $\mathrm{pH}$-specific response. These metabolomic components are also necessary to understand plant alkali tolerance. Metabolomic analyses have been applied in functional genomic research, which can reveal specific responses of biological systems to genetic and environmental changes [16]. Metabolomic analyses have been performed to investigate mechanisms related to salt stress adaptation and tolerance, such as ion homeostasis, osmotic stress, and detoxification [1]. Practically, metabonomics involves detecting and quantifying the metabolic changes with techniques such as gas chromatography-mass spectrometry (GC-MS), liquid chromatography-Fourier transform mass spectrometry (LC-FT/MS), and nuclear magnetic resonance (NMR) [17]. These technologies can be employed to accurately identify metabolomic components [18-20].

In this study, wheat seedlings were treated with salt stress (9:1 molar ratio of $\mathrm{NaCl}: \mathrm{Na}_{2} \mathrm{SO}_{4}$ ) or alkali stress (9:1 molar ratio of $\mathrm{NaHCO}_{3}: \mathrm{Na}_{2} \mathrm{CO}_{3}$ ). We systematically analyzed the metabolomic features of wheat and their dynamic responses to salt and alkali stresses using $\mathrm{GC}-$ MS technology in conjunction with multivariate data analysis [21]. The objectives of this study are to further define the metabolomic of wheat plants and determine the physiological adaptive mechanisms by which wheat tolerates alkali stress.

\section{Methods}

\section{Plant materials and growing conditions}

The seeds of wheat (T. aestivum) cv Dan-4589, a saltresistant cultivar, were sown in $34 \mathrm{~cm}$ diameter plastic pots containing $5.5 \mathrm{~kg}$ of washed sand. Each pot contained five seedlings. The pots were watered daily with $0.5 \times$ Hoagland nutrient solution at 17:00 to 18:00. All of the pots were maintained in a greenhouse at $22.5 \pm 1.5{ }^{\circ} \mathrm{C}$ at daytime and at $18.5 \pm 1.5{ }^{\circ} \mathrm{C}$ at nighttime. The plants grew at uniform irradiance of photosynthetic photon flux density of $300 \mu \mathrm{mol} \mathrm{m}^{-2} \mathrm{~s}^{-1}$.

\section{Stress treatments}

Twenty pots with seedlings growing uniformly were selected and divided randomly into four sets when the seedlings were four weeks old; each set comprised five pots. Each pot was considered a single replicate, with five replicates per set. One set was used as untreated control group, a second set was used to determine the growth index at the beginning of treatment, and the last two sets were used as stress treatment groups. Salt stress was simulated by mixing neutral salts $(\mathrm{NaCl}$ and $\mathrm{Na}_{2} \mathrm{SO}_{4}$ ) at a molar ratio of 9:1 and applying $80 \mathrm{mM}$ of salt mixture (pH 6.86, EC $8690 \mu \mathrm{s} / \mathrm{cm})$. Alkali stress was simulated by mixing $\mathrm{NaHCO}_{3}$ and $\mathrm{Na}_{2} \mathrm{CO}_{3}$ at a molar ratio of 9:1 and applying at $80 \mathrm{mM}$ of the mixture $(\mathrm{pH}$ 9.08 , EC $6550 \mu \mathrm{s} / \mathrm{cm}$ ). The pots subjected to stress treatments were watered daily with the nutrient solution containing salt mixtures at 17:00 to18:00 for $15 \mathrm{~d}$; the control plants were watered with nutrient solution only.

\section{Measurement of growth and photosynthesis indices}

Relative growth rate (RGR) is defined as [ln DW at the end of stress treatment-ln DW at the start of stress treatment]/total treatment duration [22]. The photosynthetic indices were determined at 10:00 from first fully expanded leaf blades by using a LI-6400XT portable open flow gas exchange system (Li-Cor, USA). The plants were treated with photosynthetically active radiation (PAR) of $1000 \mu \mathrm{mol} \mathrm{m} \mathrm{m}^{-2} \mathrm{~s}^{-1}$ (saturation irradiance) by using red-blue light-emitting diodes. The photosynthetic pigments were determined in accordance with previously described methods [23]. Chlorophyll (Chl) $a$ and $b$ and carotenoid (Car) contents were extracted with acetone; each sample was spectrophotometrically analyzed at 440, 645, and $663 \mathrm{~nm}$ five times in accordance with previously described methods [24].

\section{Measurement of metal elements and free ions}

Wheat leaves and roots were digested with $\mathrm{HNO}_{3}$ by microwave digestion. $\mathrm{Na}, \mathrm{K}, \mathrm{Ca}, \mathrm{Mg}, \mathrm{Fe}, \mathrm{Cu}, \mathrm{Zn}$, and $\mathrm{Mn}$ contents were determined using an atomic absorption spectrophotometer (TAS-990, Purkinje General, Beijing). After water extraction was performed, the quantities of the free ions $\left(\mathrm{NO}_{3}^{-}, \mathrm{Cl}^{-}, \mathrm{SO}_{4}^{2-}\right.$, and $\left.\mathrm{H}_{2} \mathrm{PO}_{4}^{-}\right)$were determined through ion exchange chromatography (DX300 ion chromatographic system; AS4A-SC ion-exchange column, and CD M-II electrical conductivity detector; DIONEX, Sunnyvale, USA) with a mobile phase of 1.7 $\mathrm{mM} / 1.8 \mathrm{mM} \mathrm{Na}_{2} \mathrm{CO}_{3} / \mathrm{NaHCO}_{3}$ [13].

\section{Measurement of metabolites}

Leaf extract was prepared using via the following procedures. Approximately $100 \mathrm{mg}$ of each frozen tissue sample was transferred into $2 \mathrm{ml}$ centrifuge tubes, and $60 \mu \mathrm{l}$ of water containing ribitol as an internal standard was added to each tube. After the mixtures were vortexed with $0.3 \mathrm{ml}$ of methanol and $0.1 \mathrm{ml}$ of chloroform, a 70 $\mathrm{Hz}$ grinding mill system (Jinxin Biotech LTD. Shanghai, China) was used to grind the samples for $5 \mathrm{~min}$; the 
samples were then incubated at $70{ }^{\circ} \mathrm{C}$ for $10 \mathrm{~min}$. The tubes were centrifuged at $12,000 \mathrm{rpm}$ at $4{ }^{\circ} \mathrm{C}$ for $10 \mathrm{~min}$. Supernatant $(0.35 \mathrm{ml})$ was decanted into a $2 \mathrm{ml}$ volume screw-top glass tube; the samples were dried in a vacuum concentrator at $30{ }^{\circ} \mathrm{C}$ for $2 \mathrm{~h}$. Afterward, each sample was dissolved in $80 \mu \mathrm{l}$ of methoxamine hydrochloride and incubated at $37^{\circ} \mathrm{C}$ for $2 \mathrm{~h}$. The samples were further derivatized with $\mathrm{N}, \mathrm{O}$-bis(trimethylsilyl)-trifluoroacetamide (BSTFA) containing $1 \%$ trimethylchlorosilane (TMCS) $(100 \mu \mathrm{l})$ at $70{ }^{\circ} \mathrm{C}$ for $1 \mathrm{~h} \mathrm{[25].}$

GC-TOF/MS analysis was performed using a 1D Agilent 7890 gas chromatograph system coupled with a Pegasus 4D time-of-flight mass spectrometer. The system was equipped with a DB-5MS capillary column coated in $5 \%$ diphenyl cross-linked with $95 \%$ dimethylpolysiloxane $(30 \mathrm{~m} \times 250 \mu \mathrm{m}$ inner diameter and 0.25 $\mu \mathrm{m}$ film thickness; J\&W Scientific, Folsom, CA, USA). An aliquot of the analyte $(1 \mu \mathrm{L})$ was injected in a splitless mode. Helium was used as carrier gas, the front inlet purge flow was $3 \mathrm{~mL} \mathrm{~min}{ }^{-1}$, and the gas flow rate through the column was $1 \mathrm{~mL} \mathrm{~min}^{-1}$. The initial temperature was maintained at $90{ }^{\circ} \mathrm{C}$ for $0.25 \mathrm{~min}$; temperature was increased to $180{ }^{\circ} \mathrm{C}$ at a rate of $10{ }^{\circ} \mathrm{C}$ $\min ^{-1}$ and to $240{ }^{\circ} \mathrm{C}$ at a rate of $5{ }^{\circ} \mathrm{C} \min ^{-1}$. Temperature was further increased to $285^{\circ} \mathrm{C}$ at a rate of $20{ }^{\circ} \mathrm{C} \mathrm{min}^{-1}$ for $11.5 \mathrm{~min}$. Injection, transfer line, and ion source temperatures were 280,270 , and $220{ }^{\circ} \mathrm{C}$, respectively. Energy was set at $-70 \mathrm{eV}$ in an electron impact mode. Mass spectrometry data were acquired in a full-scan mode with an $\mathrm{m} / \mathrm{z}$ range of 20 to 600 at a rate of 100 spectra per second after a solvent delay of $492 \mathrm{~s}$.

Chroma TOF 4.3X software of LECO Corporation and LECO-Fiehn Rtx 5 database were used for raw peaks exacting, the data baselines filtering and calibration of the baseline, peak alignment, deconvolution analysis, peak identification and integration of the peak area [26]. Using LECO's terminology, the data processing method should have 'Baseline', 'Peak Find', 'Caculate Area/ Height' function activated. Baseline offset was set at 1 (just above the noise), data points to be averaged for smoothing was set at automatic, peak width was set at $6 s$ and the maximum number of unknown peaks to find was set to 10000 to get as more features as possible. A signal/noise $(\mathrm{S} / \mathrm{N})$ threshold of 50:1 was used [27]. LECO-Fiehn Rtx5 library was used for searching, and the masses 85 through 600 were searched. The minimum similarity before named was assigned was set at 200 to get as more features as possible. Unique masses were used to area/height calculation.

\section{Statistical analysis}

Growth, photosynthetic activity, and inorganic ion variance and correlation were statistically analyzed using SPSS 13.0. All of the treatments were replicated five times; means and calculated standard errors (S.E.) were reported. Metabolites were identified by searching FiehnLib (GC-TOF), a commercial EI-MS library [26]. The resulting three-dimensional data, including peak number, sample name, and normalized peak area, were run in SIMCA 13.0 software package (Umetrics, Umea, Sweden) and subjected to principal component analysis (PCA) and orthogonal projections to latent structure-discriminant analysis (OPLS-DA). Non-commercial databases, including KEGG (http://www.genome.jp/kegg/), were utilized to search for metabolite pathways. Format data were uploaded in the MetaboAnalyst website (www.metaboanalyst.ca/) for further analysis [28].

\section{Results}

\section{Growth, Photosynthesis, and Pigment contents}

The growth of wheat seedling leaves and roots decreased under salinity stress compared with that of the control group; the growth of these parts was reduced to a greater extent under alkali stress than under salt stress (Figs. 1a and b, $p<0.05$ ). The photosynthetic indices of plants exposed to salt and alkali stress were lower than those of the control plants; however, these parameters decreased sharply under alkali stress (Figs. 1c-f, $p<$ $0.05)$. Pigment contents were not significantly affected by salt stress, but $\mathrm{Chl}$ and Car contents decreased remarkably in plants under alkali stress compared with those in the control plants (Figs. $1 \mathrm{~g}-\mathrm{i}, p<0.05$ ).

\section{Metal element and free ion contents}

In response to salt and alkali stress for $15 \mathrm{~d}$, the $\mathrm{Na}$ content of leaves and roots increased, whereas $\mathrm{K}$ content decreased; nevertheless, the magnitude of these changes was greater under alkali stress than under salt stress (Figs. 2a and b, $p<0.05$ ). Ca content in leaves was reduced under both stress conditions. Ca content decreased under salt stress, whereas $\mathrm{Ca}$ content in roots increased under alkali stress (Fig. 2c, $p<0.05$ ). Mg content in leaves slightly changed, whereas $\mathrm{Mg}$ content in roots significantly decreased under salt and alkali stress (Fig. 2d, $p<0.05$ ). Fe and $\mathrm{Cu}$ accumulation in leaves was not affected by both stress conditions compared with that in the control plants (Figs. 2e and f, $p<0.05$ ). By contrast, $\mathrm{Fe}$ and $\mathrm{Cu}$ contents decreased in roots; this decrease was significantly greater under alkali stress than under salt stress (Figs. 2e and f, $p<0.05$ ). Zn content in wheat seedlings decreased under salt and alkali stress, although the decrease under alkali stress was significantly lower than that under salt stress (Fig. $2 \mathrm{~g}, p<0.05$ ). Mn content was not significantly affected by salt stress; by contrast, Mn content significantly decrease in leaves and roots, as induced by alkali stress (Fig. $2 \mathrm{~h}, p<0.05$ ). $\mathrm{Cl}^{-}$ content was slightly affected by alkali stress; conversely, $\mathrm{Cl}^{-}$content was significantly increased by salt stress 

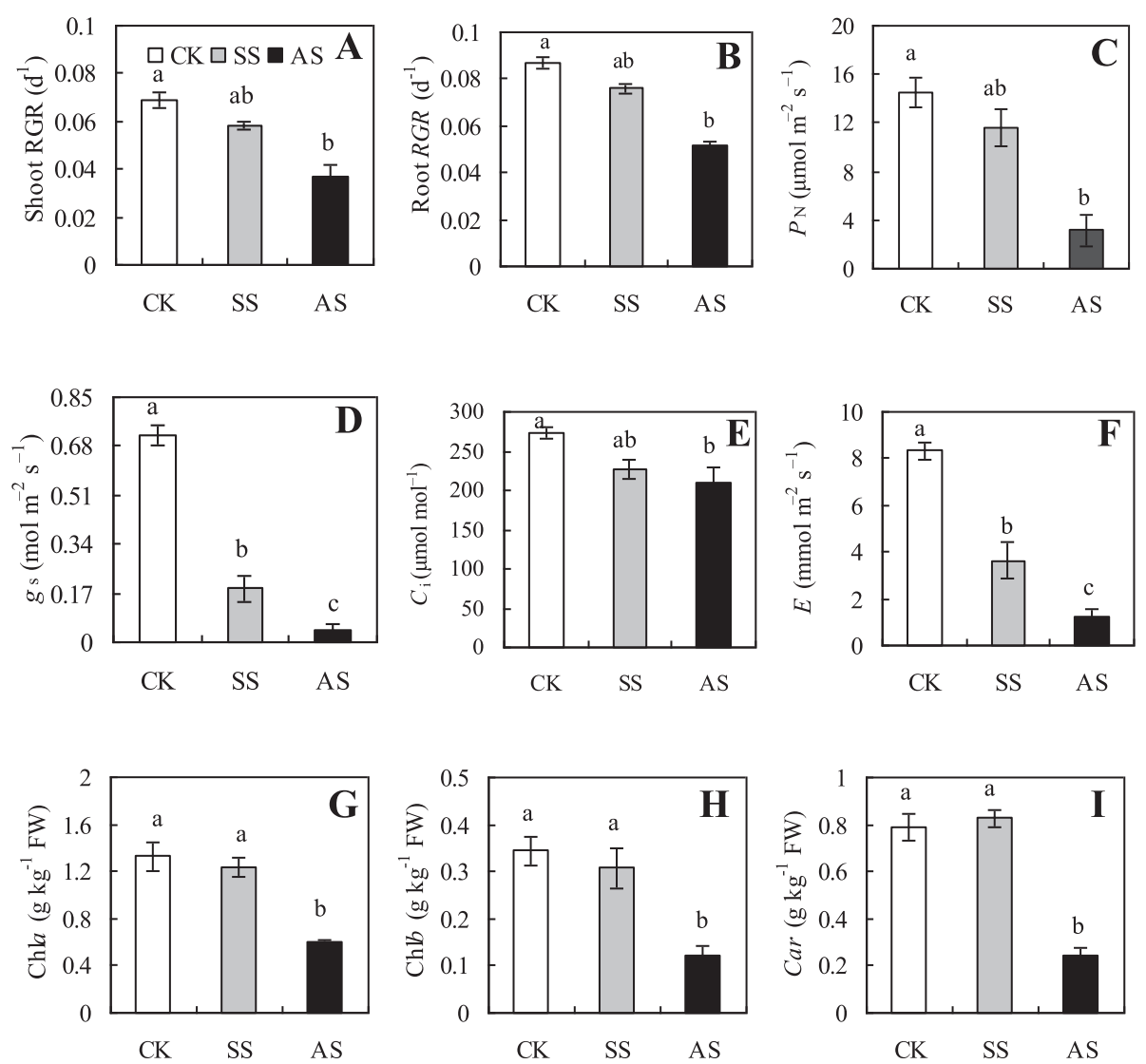

Fig. 1 Effects of salt stress (SS) and alkali stress (AS) on relative growth rate $(R G R)$ of leaves $(\mathbf{a})$ and roots $(\mathbf{b})$, net photosynthetic rate $\left(P_{N}\right)(\mathbf{c})$, stomatal conductance $\left(g_{s}\right)(\mathbf{d})$, intercellular $\mathrm{CO}_{2}$ concentration $\left(C_{\mathrm{i}}\right)(\mathbf{e})$, transpiration rate $(E)(\mathbf{f})$, chlorophyll $a(C h l a)(\mathbf{g})$ and $b(C h l b)$ contents $(\mathbf{h})$, and carotenoid (Car) (i) content of wheat. Values are means of five replicates. Means followed by different letters in the same stress type are significantly different at $p<0.05$ according to Duncan's method

(Fig. $2 \mathrm{i}, p<0.05$ ). $\mathrm{NO}_{3}^{-}$and $\mathrm{H}_{2} \mathrm{PO}_{4}^{-}$contents were also not significantly affected by salt stress; $\mathrm{NO}_{3}^{-}$and $\mathrm{H}_{2} \mathrm{PO}_{4}^{-}$ contents were decreased dramatically by alkali stress (Figs. $2 \mathrm{j}$ and $\mathrm{k}, p<0.05$ ). $\mathrm{SO}_{4}^{2-}$ content was not affected by salt and alkali stress (Fig. 2l, $p<0.05$ ).

\section{Metabolic changes in response to control, salt stress, and alkali stress treatments}

The metabolic changes in leaves and roots of wheat seedlings subjected to control, salt stress, and alkali stress treatments were determined through GC-MS to reveal the physiological responses and adaptive strategies of wheat to salinity stress. A significant difference exists in the metabolite profiles between samples under control and salinity stress treatments. A total of 75 metabolites were identified and determined in leaves and roots. Based on the PCA results, a separation of samples under control treatment, salt stress, and alkali stress in leaves and roots (Fig. 3 and Additional files 1 and 2) was observed. The control and salinity treatment samples in leaves and roots were separated by the first principal component (PC1), representing $50.9 \%$ and $73.1 \%$ of the total variation (Figs. 3a and b). Pairwise comparative OPLS-DA was conducted with one orthogonal and one predictive component calculated for all models derived from two classes of samples to obtain detailed information on metabolic alterations under salt and alkali stress and significance of metabolites contributing to the alterations. In this research, OPLS-DA models revealed the separation between samples within control and salinity treatments. The score plots of OPLS-DA results showed clear separation between wheat plants under salt and alkali stress and control plants with good model quality (Fig. $3 B_{1}$ and $C_{1} ; B_{2}$ and $C_{2}$ ). These differences were also observed in the score plots between salt stress and alkali stress in leaves and roots, respectively (Figs. $3 D_{1}$ and $3 \mathrm{D}_{2}$ ).

\section{Metabolic profiles in response to salt and alkali stress in wheat seedlings}

Based on the results of PCA and OPLS-DA, the responses of metabolites to salt stress and alkali stress were different in leaves and roots. The response of 11 and 5 metabolites under salt stress and 7 and 36 metabolites under alkali 

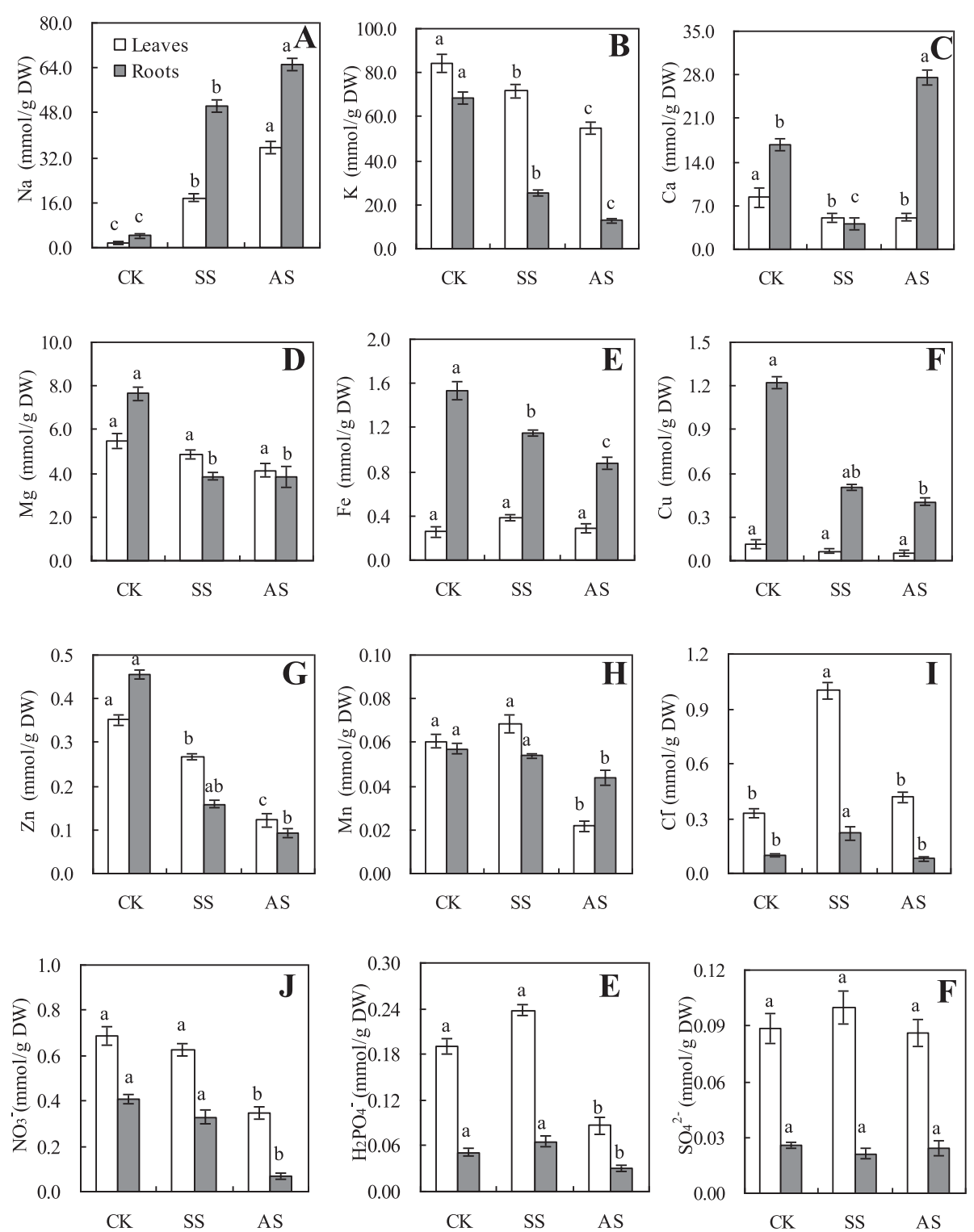

Fig. 2 Effects of salt stress (SS) and alkali stress (AS) on the contents of metal elements and free ions in wheat seedling leaves and roots. Metal elements $\mathrm{Na}(\mathbf{a}), \mathrm{K}(\mathbf{b}), \mathrm{Ca}(\mathbf{c}), \mathrm{Mg}(\mathbf{d}), \mathrm{Fe}(\mathbf{e}), \mathrm{Cu}(\mathbf{f}), \mathrm{Zn}(\mathbf{g})$, and $\mathrm{Mn}(\mathbf{h})$; free ions $\mathrm{Cl}^{-}(\mathbf{i}), \mathrm{NO}_{3}^{-}(\mathbf{j}), \mathrm{H}_{2} \mathrm{PO}_{4}^{-}(\mathbf{k})$, and $\mathrm{SO}_{4}^{2-}(\mathbf{l})$. Values are means of five replicates. Means followed by different letters in the same stress type are significantly different at $p<0.05$ according to Duncan's method

stress remarkably increased and decreased, respectively, in leaves of wheat seedlings (Fig. 4, leaves). Following prestress, salt stress caused an increase in levels of glucose, glucose-6-P, fructose-6-P, 3-PGA, and PEP, which are involved in glycolysis, and in levels of fructose, trehalose, proline, valine, isoleucine, and leucine. By contrast, salt stress resulted in a decrease in levels of fumaric acid and malic acid, which are involved in the TCA cycle, and in levels of maltose, shikimic acid, and quinic acid, which are involved in the shikimate pathway. Under alkali stress, the levels of some amino acids and sugars increased, including proline, lysine, sucrose, sorbitol, trehalose, lyxose, and gentiobiose; however, glycolysis was significantly inhibited under alkali stress, thereby decreasing the levels of glucose-6-P, fructose-6-P, and PEP. Furthermore, the TCA cycle, which is associated with glycolysis pathway, was inhibited under alkali stress, as shown by lower citric acid, $\alpha$-ketoglutaric acid, and fumaric acid levels than the control plants. Shikimate pathway and GABA shunt metabolites were inhibited under alkali stress, resulting in a decrease in shikimic acid, quinic acid, phenylalanine, GABA, and glutamate levels (Table 1).

In roots, the response of 9 and 16 metabolites under salt stress and 8 and 44 metabolites under alkali stress significantly increased and decreased, respectively (Fig. 4, roots). Salt stress caused a significant increase in levels 


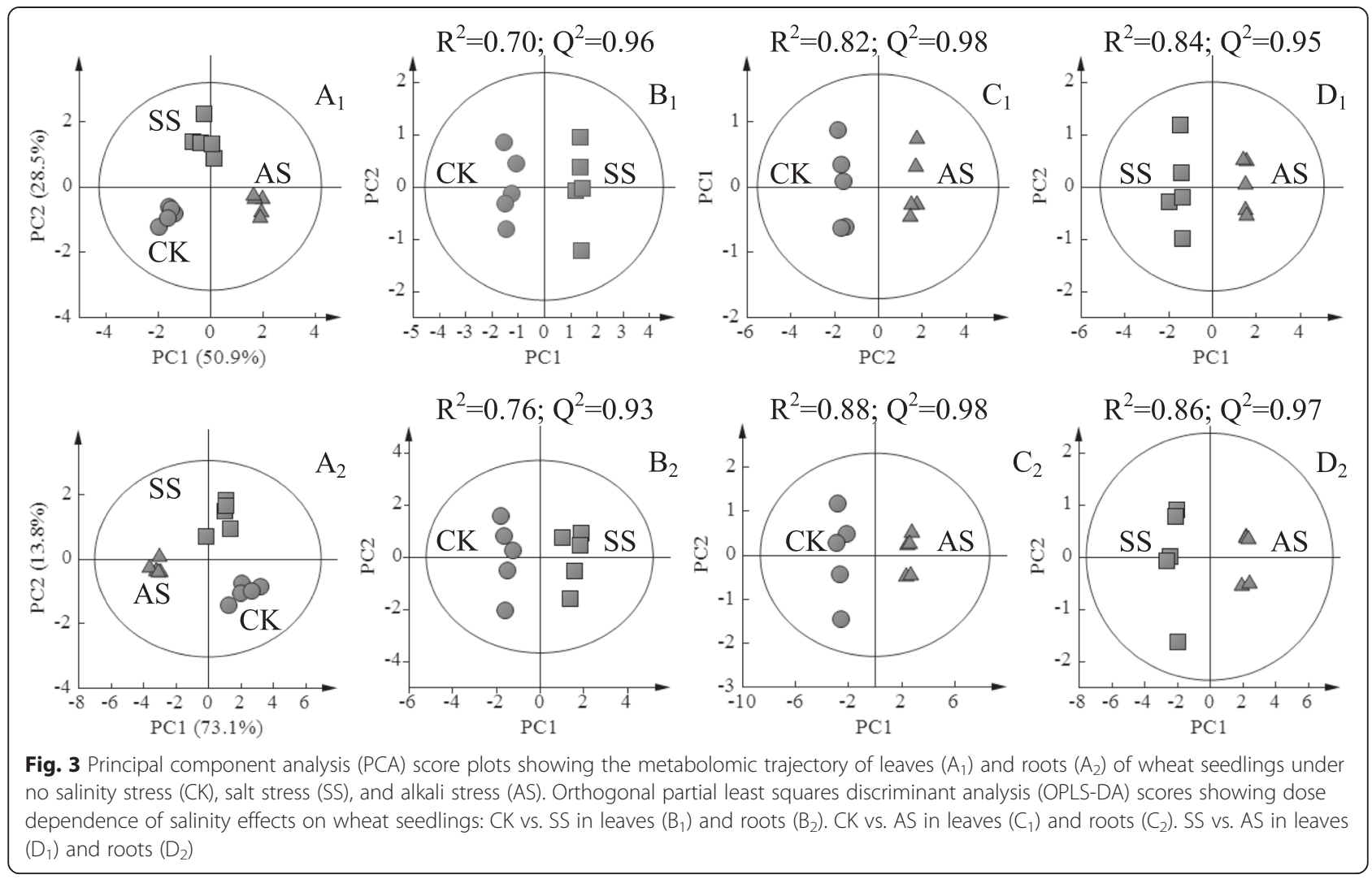

of proline, sucrose, myo-inositol, xylitol, galactinol, raffinose, gentiobiose, galactose, phosphate, and diglycerol compared with the control treatment; by contrast, levels of glucose and glucose-6-P, which are involved in glycolysis, some amino acids, such as GABA, valine, and asparagine, and some sugars, including sorbitol, xylose, and lyxose, decreased remarkably in roots. Alkali stress significantly affected the TCA cycle; citric acid, aconitic acid, $\alpha$-ketoglutaric acid, succinic acid, and fumaric acid were significantly increased, indicating that energy production in the TCA cycle was enhanced by alkali stress. Furthermore, levels of shikimic acid, quinic acid, and diglycerol were significantly increased. Most of the amino acids and sugars in roots decreased under alkali stress compared with those of the control treatment, although this decrease was significantly lower than that under salt stress. The results also showed that glycolysis was inhibited in roots under alkali stress (Table 2).

\section{Discussion}

\section{Growth, Photosynthesis, and Pigment contents}

In the seedling stage, plants are sensitive to adverse external factors, including abiotic stress [29]. RGR reflects the condition of the plant and is thus considered as a useful index in determining the degree of stress of a plant. In general, salinity inhibits growth and can even lead to plant death [1]. However, our results showed that $R G R$ decreased under salinity stress, with the extent of the decrease under alkali stress being clearly greater than that under salt stress. This indicates that salt stress and
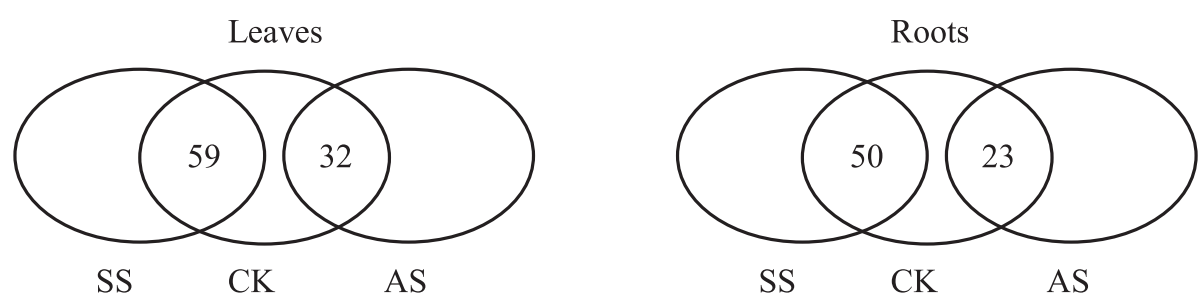

Fig. 4 Global comparison of metabolic profiles in leaves and roots under no salinity stress (CK), salt stress (SS), and alkali stress (AS). A total of 77 metabolites were identified in this study, and the numbers in the figure indicate the numbers of metabolites with no significant difference in their contents for each comparison 
alkali stress are distinct types of stress and that the injurious effects of alkali stress on plants are more severe than those of salt stress. The injurious effect of salt stress is commonly caused by low-water potential and ion toxicity; by contrast, alkali stress involves high-pH stress, in addition to these two stress factors [12, 30]. High $\mathrm{pH}$ leads to lack of protons and the destruction or inhibition of transmembrane electrochemical potential gradients in cells. The effects of salt stress and alkali stress on photosynthetic activity led us to investigate the mechanisms involved in more detail by examining photosynthesis and pigment contents as indices of stress, since this could provide insights into the nature of the stress-induced damage to the photosynthetic apparatus [12]. In general, $P_{\mathrm{N}}$ of a plant usually decreases under stress. In the present study, $P_{\mathrm{N}}$ of wheat was not low under salt stress but decreased sharply under alkali stress. This result implied that salt stress and alkali stress were two distinct stress conditions; the resistance of wheat to salt stress was stronger than that to alkali stress. $g_{\mathrm{s}}$ was closely correlated with the change in environment water potential. The responses of $g \mathrm{~s}$ in wheat to salinity stress indicate that the change in $g_{s}$ could respond to the decrease in environment water potential and intracellular $W C$. The decrease in $g_{\mathrm{s}}$ might cause the obvious decreases of $E$ and $C_{\mathrm{i}}$ under alkali stress [31]. $\mathrm{Chl}$ and $\mathrm{Car}$ are the main photosynthetic pigments of higher plants. The contents of $\mathrm{Chl}$ and $\mathrm{Car}$ was stimulated under salt stress, but decreased sharply under alkali stress. This implies that alkali stress caused $\mathrm{Mg}$ precipitation and led to inhibition of Chl synthesis, and it might enhance the activity of the Chl-degrading enzyme chlorophyllase [30, 32]. These results agree with those obtained by Guo et al. and Yang et al. [12, 30, 33, 34].

\section{Metal elements and free ions}

In higher plants, the cytoplasm usually contains low $\mathrm{Na}^{+}$ concentrations and high $\mathrm{K}^{+}$concentrations to maintain the function of essential enzyme processes; this state is closely maintained during osmotic adjustment [1, 24]. The results indicated that $\mathrm{Na}^{+}$uptake competes with $\mathrm{K}^{+}$ uptake under salt and alkali stresses and that $\mathrm{K}^{+}$percentage of total ionic content decreases, whereas $\mathrm{Na}^{+}$ percentage increases; the effects are more pronounced under alkali stress than under salt stress [35]. A considerable response of wheat plant to alkali stress is the strong stimulation of accumulation of $\mathrm{Na}$ and $\mathrm{Ca}$ in roots by alkali compared with accumulation under salt stress. Under salt stress, the $\mathrm{Na}^{+}$metabolism of plants has at least three processes: compartmentalization (at cellular and/or tissue levels), exclusion (from shoots into roots or from roots to the rhizosphere), and transportation (in vasculature) of the ions. Many plant species have a $\mathrm{Na}^{+}$exclusion mechanism that is dependent on a $\mathrm{H}^{+}$ gradient across a root cell membrane [36]. In Arabidopsis, the salt overly sensitive 1 (SOS1) protein functions in $\mathrm{Na}^{+}$exclusion from root epidermal cells into the rhizosphere. SOS1 protein plays an important role in the control of long-distance transport from roots to shoots and contributes to $\mathrm{Na}^{+}$exclusion from roots to soil [36]. This may be the basis of alkali injury. Tolerance of plants to $\mathrm{Na}^{+}$ stress relies on $\mathrm{Na}^{+}$compartmentalization at the cellular and tissue levels, $\mathrm{Na}^{+}$exclusion, and control of long-distance transport in vasculatures. In Arabidopsis, the $\mathrm{Ca}^{2+}$-responsive AtSOS3-AtSOS2 (AtCIPK24-AtCBL4) protein kinase pathway mediates regulation of the expression and activities of $\mathrm{Na}^{+}$transporters, such as AtSOS1 and AtNHX, which is a $\mathrm{Na}^{+} / \mathrm{H}^{+}$exchanger that mediates $\mathrm{Na}^{+}$compartmentalization into vacuoles, with $\mathrm{Ca}^{2+}$ being the key signal component in the SOS system [24] In summary, on the basis of the above data, we can think that $\mathrm{Ca}^{2+}$ plays an important role in plant alkali tolerance to exclude $\mathrm{Na}$. In the present study, salt stress reduces $\mathrm{Ca}$ accumulation in wheat roots, but alkali stress strongly enhances its accumulation in roots. Under alkali stress, increasing $\mathrm{Ca}$ concentration can immediately trigger SOS-Na excluding system and reduce $\mathrm{Na}$ injury to shoots. Plants usually accumulate inorganic anions such as $\mathrm{Cl}^{-}, \mathrm{NO}_{3}^{-}$, and $\mathrm{SO}_{4}^{2-}$ to maintain $\mathrm{Na}^{+}$levels $[1,13] \cdot \mathrm{Cl}^{-}$levels increased sharply in wheat under salt stress to balance the massive influx of $\mathrm{Na}^{+}$, which also caused a severe loss of inorganic negative charges because of the decreased levels of $\mathrm{NO}_{3}^{-}$and $\mathrm{H}_{2} \mathrm{PO}_{4}^{-}$.

\section{Metabolic responses to salt and alkali stresses in wheat seedlings}

Osmotic stress and excessive $\mathrm{Na}^{+}$affect root functions when plants are subjected to salinity stress, which induces generation of reactive oxygen species (ROS), such as $\mathrm{O}_{2}^{-}$, and causes intracellular hyperammonia [37]. Proline is known to play an important role in higher plants in response to osmotic and salinity stress by protecting plant cell membranes and proteins and functioning as a ROS scavenger [38]. In this study, proline accumulated in the cytoplasm of wheat seedlings in response to salinity stress, helping in balancing the osmotic pressure in the vacuoles in response to influx of $\mathrm{Na}^{+}$. Proline increase was accompanied with a significant decrease in levels of transamination-related metabolites Glu and GABA, implying that salinity stress promotes Glu conversion into proline with $\Delta^{1}$-pyrroline-5-carboxylate synthetase (Figs. 5 and 6). Many studies have shown that the accumulation of some sugars can counter the effects of increased salinity by increasing the osmotic potential to avoid stress [39]. Our results showed that the sugar contents of the wheat seedlings increased in response to salt stress; however, a dramatic decrease in sugar levels 


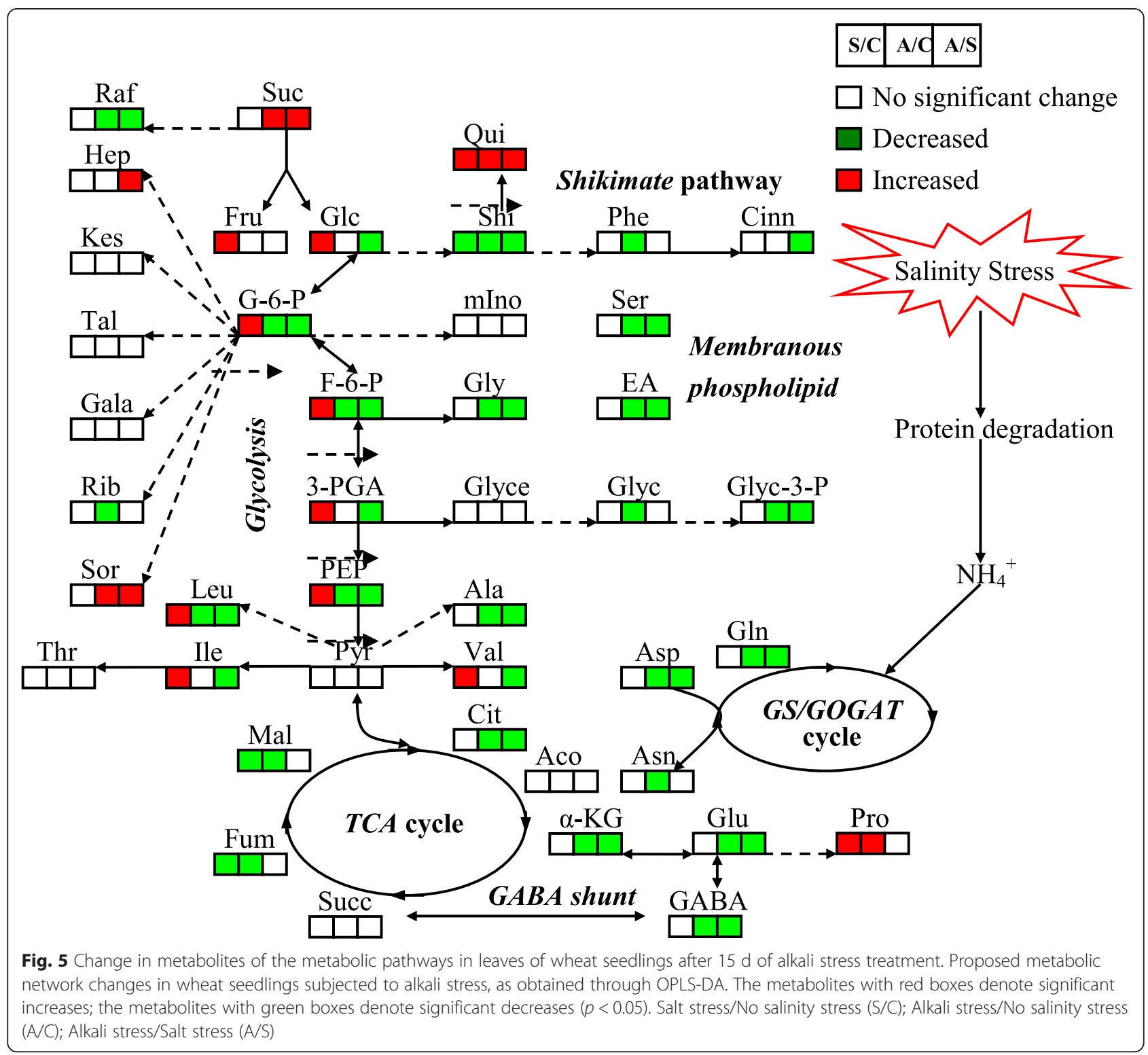

was found under alkali stress. In plant cells, sugars were derived from photosynthesis, gluconeogenesis, and degradation of polysaccharides [5, 39]. Since the apparent photosynthetic rate was reported to be similar under control and salt stress, this implies that gluconeogenesis was probably promoted under salt stress to maintain osmotic balance, as well as for sugars to function as carbon storage. The severe negative effect of alkali stress on sugar synthesis and storage may reflect the toxic levels of $\mathrm{Na}^{+}$accumulating in plant cells in a high-pH environment, implying ROS detoxification capacity had been setback by high $\mathrm{pH}$. Our data suggest that sugar accumulation is not a simple passive response to osmotic stress, but rather a result of active metabolic regulation after sensing high $\mathrm{pH}$ levels and corresponding alkali stress indicators.
Metabolite responses to salt stress and alkali stress differ. In this study, glycolysis and amino acid synthesis in leaves were likely enhanced under salt stress; by contrast, these processes were inhibited under alkali stress (Figs. 5 and 6). Furthermore, the TCA cycle was inhibited in leaves under salt and alkali stress (Figs. 5 and 6). The results suggest that active synthesis is a basic response of leaves to tolerate salt stress, and energy is not important for leaves to develop salinity stress. Furthermore, an increase in Val, Ile, and Leu was probably associated with inhibited protein biosynthesis or enhanced protein degradation because wheat seedling growth was inhibited under prolonged salt stress; Val, Ile, and Leu are all precursors in the biosynthesis of polyphenols, which function as plant endogenous antioxidants (Figs. 1a and 5). Under alkali 


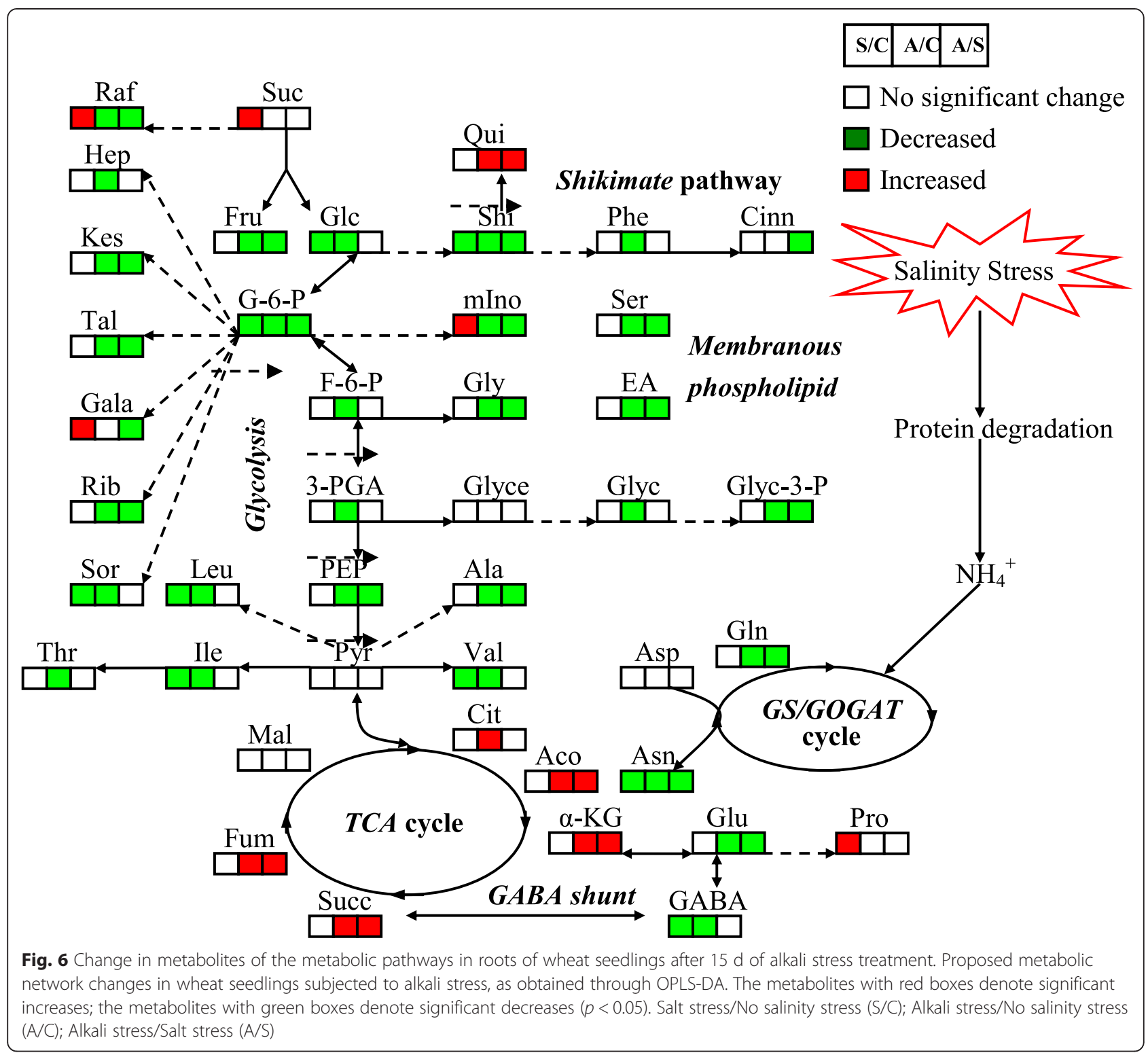

stress, the photosynthetic rate decreased significantly, causing reduced production of reducing force and limited $\mathrm{N}$ metabolism, which in turn reduces the production of amino acids and inhibits glycolysis (Figs. 5 and 6). The decrease in photosynthetic rate may also affect photorespiration and induce the decrease in photorespiration rate. Under salt stress, TCA cycle and organic acid accumulation were enhanced, but glycolysis and amino acid synthesis were inhibited in roots under alkali stress (Fig. 6). The results indicate that energy and high level of organic acids may be the key adaptive mechanism by which wheat seedlings maintain their intracellular ion balance under alkali stress (Figs. 5 and 6). Organic acids could play a central role in the regulation of intracellular $\mathrm{pH}$ by accumulating in vacuoles to neutralize excess cations [13, 32, 34]. Either or both $\mathrm{Na}^{+}$and $\mathrm{NO}_{3}^{-}$ions may trigger a signal transduction cascade culminating in the stimulation of organic acid anion synthesis because the main factors contributing to the negative charge deficit in wheat seedlings were excess $\mathrm{Na}^{+}$and limited $\mathrm{NO}_{3}^{-}$; as a result, various organic acids accumulated. In wheat roots, decrease in amino acids caused by alkali stress may be attributed to limitation of nitrogen metabolism by alkali stress (Fig. 6). Plant roots absorb nitrate $\left(\mathrm{NO}_{3}^{-}\right)$, ammonium $\left(\mathrm{NH}_{4}^{+}\right)$, and other nutrients from soil using a variety of transporters [40]. For example, AMT protein family members transport $\mathrm{NH}_{4}^{+}$, whereas $\mathrm{NRT}$ protein family members transport nitrate. $\mathrm{NH}_{4}^{+}$and $\mathrm{NO}_{3}^{-}$uptake mediated by AMT and NRT possibly relies on transmembrane proton gradient [41]. Under alkali stress, the lack of external protons may weaken AMT and NRT 
activities on the root plasma membrane; thus, $\mathrm{NH}_{4}^{+}$and $\mathrm{NO}_{3}^{-}$uptake is possibly reduced. Indeed, we observed that alkali stress decreased $\mathrm{NO}_{3}^{-}$content in wheat roots to almost zero (Table 1). $\mathrm{NO}_{3}^{-}$is reduced to nitrite by nitrate reductase (NR) and then to $\mathrm{NH}_{4}^{+}$by nitrite reductase (NiR).
$\mathrm{NH}_{4}^{+}$from both nitrate reduction and soil are incorporated into organic molecules by glutamine synthetase (GS) and glutamate synthase (Fd-GOGAT and NADH-GOGAT) or through the alternative glutamate dehydrogenase (GDH) pathway [40]. Lack of $\mathrm{NO}_{3}^{-}$in wheat roots can decrease

Table 1 Relative concentration and fold changes of major metabolites in leaves of wheat seedlings after $15 \mathrm{~d}$ of salt and alkali treatments

\begin{tabular}{|c|c|c|c|c|c|c|c|}
\hline \multirow[t]{2}{*}{ Metabolic pathways } & \multirow[t]{2}{*}{ Metabolites } & \multicolumn{3}{|c|}{ Relative concentration } & \multicolumn{3}{|c|}{ Fold changes } \\
\hline & & CK & SS & AS & $\log _{2}^{(\mathrm{SS} / \mathrm{CK})}$ & $\log _{2}^{(\mathrm{AS} / \mathrm{CK})}$ & $\log _{2}^{(\mathrm{AS} / \mathrm{SS})}$ \\
\hline \multirow[t]{6}{*}{ TCA cycle } & Cit & 29.28 & 22.00 & 6.81 & -0.41 & $-2.10^{\mathrm{a}}$ & $-1.69^{\mathrm{a}}$ \\
\hline & Aco & 1.25 & 1.02 & 0.88 & -0.30 & -0.51 & -0.21 \\
\hline & $a-K G$ & 0.55 & 0.52 & 0.26 & -0.09 & $-1.09^{\mathrm{a}}$ & $-1.00^{\mathrm{a}}$ \\
\hline & Succ & 9.17 & 6.45 & 5.28 & -0.51 & -0.79 & -0.29 \\
\hline & Fum & 3.70 & 1.65 & 1.02 & $-1.16^{\mathrm{a}}$ & $-1.86^{\mathrm{a}}$ & -0.70 \\
\hline & Mal & 19.01 & 8.10 & 5.86 & $-1.23^{\mathrm{a}}$ & $-1.70^{\mathrm{a}}$ & -0.47 \\
\hline \multirow[t]{6}{*}{ Glycolysis } & $\mathrm{Glc}$ & 5.66 & 71.66 & 9.08 & $3.66^{\mathrm{a}}$ & 0.68 & $-2.98^{\mathrm{a}}$ \\
\hline & G6P & 0.56 & 1.29 & 0.27 & $1.19^{\mathrm{a}}$ & $-1.06^{\mathrm{a}}$ & $-2.25^{\mathrm{a}}$ \\
\hline & F6P & 0.54 & 1.32 & 0.23 & $1.30^{\mathrm{a}}$ & $-1.24^{\mathrm{a}}$ & $-2.54^{\mathrm{a}}$ \\
\hline & $3-P G A$ & 0.35 & 0.92 & 0.31 & $1.38^{\mathrm{a}}$ & -0.18 & $-1.56^{\mathrm{a}}$ \\
\hline & Pyr & 0.68 & 0.63 & 0.57 & -0.10 & -0.25 & -0.15 \\
\hline & PEP & 0.15 & 0.62 & 0.07 & $2.05^{\mathrm{a}}$ & $-1.15^{\mathrm{a}}$ & $-3.19^{a}$ \\
\hline \multirow[t]{14}{*}{ Amino acids } & Glu & 270.41 & 220.74 & 103.83 & -0.29 & $-1.38^{\mathrm{a}}$ & $-1.09^{\mathrm{a}}$ \\
\hline & GABA & 101.70 & 85.20 & 42.42 & -0.26 & $-1.26^{\mathrm{a}}$ & $-1.01^{\mathrm{a}}$ \\
\hline & Ala & 67.72 & 69.28 & 24.26 & 0.03 & $-1.48^{\mathrm{a}}$ & $-1.51^{\mathrm{a}}$ \\
\hline & Asp & 51.33 & 32.36 & 11.90 & -0.67 & $-2.11^{\mathrm{a}}$ & $-1.44^{\mathrm{a}}$ \\
\hline & Gly & 21.96 & 13.17 & 4.47 & -0.74 & $-2.30^{\mathrm{a}}$ & $-1.56^{\mathrm{a}}$ \\
\hline & Thr & 9.54 & 7.76 & 7.12 & -0.30 & -0.42 & -0.12 \\
\hline & Ser & 8.58 & 9.42 & 2.56 & 0.13 & -1.74 & -1.88 \\
\hline & Val & 2.92 & 5.79 & 2.90 & $0.99^{\mathrm{a}}$ & -0.01 & $-1.00^{\mathrm{a}}$ \\
\hline & Pro & 0.39 & 1.31 & 1.29 & $1.73^{\mathrm{a}}$ & $1.72^{\mathrm{a}}$ & -0.02 \\
\hline & Phe & 0.51 & 0.42 & 0.24 & -0.29 & $-1.10^{\mathrm{a}}$ & -0.82 \\
\hline & Gln & 0.60 & 0.37 & 0.09 & -0.68 & $-2.72^{\mathrm{a}}$ & $-2.04^{\mathrm{a}}$ \\
\hline & Ile & 0.42 & 2.89 & 0.48 & $2.77^{\mathrm{a}}$ & 0.19 & $-2.58^{\mathrm{a}}$ \\
\hline & Leu & 0.07 & 0.42 & 0.03 & $2.66^{a}$ & $-1.02^{\mathrm{a}}$ & $-3.68^{\mathrm{a}}$ \\
\hline & Asn & 0.06 & 0.05 & 0.03 & -0.17 & $-1.12^{\mathrm{a}}$ & -0.96 \\
\hline \multirow[t]{10}{*}{ Sugars and polyols } & Fru & 162.82 & 327.02 & 224.24 & $1.01^{\mathrm{a}}$ & 0.46 & -0.54 \\
\hline & Suc & 0.54 & 0.92 & 1.72 & 0.76 & $1.67^{\mathrm{a}}$ & $0.90^{\mathrm{a}}$ \\
\hline & Tal & 29.78 & 25.25 & 22.97 & -0.24 & -0.37 & -0.14 \\
\hline & Kes & 0.29 & 0.40 & 0.33 & 0.45 & 0.19 & -0.26 \\
\hline & Нер & 0.56 & 0.36 & 0.85 & -0.64 & 0.60 & $1.24^{\mathrm{a}}$ \\
\hline & mlno & 20.79 & 18.76 & 15.98 & -0.15 & -0.38 & -0.23 \\
\hline & Sor & 0.52 & 0.39 & 2.35 & -0.42 & $2.16^{\mathrm{a}}$ & $2.58^{\mathrm{a}}$ \\
\hline & Rib & 30.99 & 19.85 & 14.86 & -0.64 & $-1.06^{\mathrm{a}}$ & -0.42 \\
\hline & Gala & 23.45 & 18.76 & 16.26 & -0.32 & -0.53 & -0.21 \\
\hline & Raf & 14.24 & 13.45 & 4.35 & -0.08 & $-1.71^{\mathrm{a}}$ & $-1.63^{\mathrm{a}}$ \\
\hline
\end{tabular}

The relative concentration of each metabolite is an average of data from six biological replicates obtained through GC-MS. Fold changes were calculated using 
NR, GS, and glutamate synthase activities because these enzymes are induced by $\mathrm{NO}_{3}^{-}$, which should directly limit the synthesis of amino acids. This may affect almost all metabolic processes including the processes observed in our metabolic data.

\section{Conclusions}

This paper indicated that salt and alkali stresses are two different stresses, the inhibitory effects of alkali stress on wheat growth and photosynthesis were greater than those of salt stress. Alkali stress induced the production

Table 2 Relative concentration and fold changes of major metabolites in roots of wheat seedlings after $15 \mathrm{~d}$ of salt and alkali treatments

\begin{tabular}{|c|c|c|c|c|c|c|c|}
\hline \multirow{2}{*}{$\begin{array}{l}\text { Metabolic } \\
\text { pathways }\end{array}$} & \multirow[t]{2}{*}{ Metabolites } & \multicolumn{3}{|c|}{ Relative concentration } & \multicolumn{3}{|c|}{ Fold changes } \\
\hline & & CK & SS & AS & $\log _{2}^{(\mathrm{SS} / \mathrm{CK})}$ & $\log _{2}^{(\mathrm{AS} / \mathrm{CK})}$ & $\log _{2}^{(\mathrm{AS} / \mathrm{SS})}$ \\
\hline \multirow[t]{6}{*}{ TCA cycle } & Cit & 70.05 & 114.56 & 166.40 & 0.71 & $1.25^{\mathrm{a}}$ & 0.54 \\
\hline & Aco & 1.37 & 1.44 & 2.87 & 0.07 & $1.07^{\mathrm{a}}$ & $1.00^{\mathrm{a}}$ \\
\hline & $a-K G$ & 0.15 & 0.27 & 0.59 & 0.81 & $1.94^{\mathrm{a}}$ & $1.13^{\mathrm{a}}$ \\
\hline & Succ & 17.80 & 11.37 & 86.02 & -0.65 & $2.27^{\mathrm{a}}$ & $2.92^{\mathrm{a}}$ \\
\hline & Fum & 1.25 & 1.04 & 7.21 & -0.27 & $2.53^{\mathrm{a}}$ & $2.80^{\mathrm{a}}$ \\
\hline & Mal & 10.44 & 16.43 & 18.29 & 0.65 & 0.81 & 0.15 \\
\hline \multirow[t]{6}{*}{ Glycolysis } & Glc & 22.49 & 11.19 & 9.45 & $-1.01^{\mathrm{a}}$ & $-1.25^{\mathrm{a}}$ & -0.24 \\
\hline & G6P & 0.49 & 0.23 & 0.10 & $-1.09^{\mathrm{a}}$ & $-2.32^{\mathrm{a}}$ & $-1.23^{\mathrm{a}}$ \\
\hline & F6P & 0.19 & 0.10 & 0.05 & -0.95 & $-1.96^{\mathrm{a}}$ & $-1.01^{\mathrm{a}}$ \\
\hline & 3-PGA & 0.44 & 0.27 & 0.14 & -0.72 & $-1.63^{\mathrm{a}}$ & -0.92 \\
\hline & Pyr & 0.49 & 0.52 & 0.39 & 0.09 & -0.34 & -0.43 \\
\hline & PEP & 0.64 & 0.61 & 0.25 & -0.07 & $-1.34^{\mathrm{a}}$ & $-1.27^{\mathrm{a}}$ \\
\hline \multirow[t]{14}{*}{ Amino acids } & Glu & 134.99 & 141.95 & 36.04 & 0.07 & $-1.91^{\mathrm{a}}$ & $-1.98^{\mathrm{a}}$ \\
\hline & GABA & 104.32 & 46.87 & 33.20 & $-1.15^{\mathrm{a}}$ & $-1.65^{\mathrm{a}}$ & -0.50 \\
\hline & Ala & 151.29 & 98.92 & 14.73 & -0.61 & $-3.36^{\mathrm{a}}$ & $-2.75^{\mathrm{a}}$ \\
\hline & Asp & 12.33 & 7.44 & 7.28 & -0.73 & -0.76 & -0.03 \\
\hline & Gly & 7.45 & 4.09 & 0.97 & -0.87 & $-2.94^{\mathrm{a}}$ & $-2.07^{\mathrm{a}}$ \\
\hline & Thr & 9.71 & 4.95 & 1.50 & -0.97 & $-2.70^{\mathrm{a}}$ & $-1.7^{\mathrm{a}} 2$ \\
\hline & Ser & 16.05 & 11.41 & 2.22 & -0.49 & $-2.85^{\mathrm{a}}$ & $-2.36^{\mathrm{a}}$ \\
\hline & Val & 17.42 & 8.19 & 5.28 & $-1.09^{\mathrm{a}}$ & $-1.72^{\mathrm{a}}$ & -0.64 \\
\hline & Pro & 8.54 & 17.36 & 14.58 & $1.02^{\mathrm{a}}$ & 0.77 & -0.25 \\
\hline & Phe & 0.41 & 0.19 & 0.16 & $-1.08^{\mathrm{a}}$ & $-1.31^{\mathrm{a}}$ & -0.23 \\
\hline & Gln & 0.11 & 0.12 & 0.02 & 0.17 & $-2.20^{\mathrm{a}}$ & $-2.36^{a}$ \\
\hline & lle & 7.50 & 3.06 & 2.51 & $-1.29^{\mathrm{a}}$ & $-1.58^{\mathrm{a}}$ & -0.29 \\
\hline & Leu & 0.63 & 0.19 & 0.14 & $-1.73^{\mathrm{a}}$ & $-2.18^{\mathrm{a}}$ & -0.44 \\
\hline & Asn & 16.66 & 3.07 & 1.29 & $-2.44^{\mathrm{a}}$ & $-3.69^{a}$ & $-1.25^{\mathrm{a}}$ \\
\hline \multirow[t]{10}{*}{ Sugars and polyols } & Fru & 860.33 & 684.72 & 237.87 & -0.33 & $-1.85^{\mathrm{a}}$ & $-1.53^{\mathrm{a}}$ \\
\hline & Suc & 96.20 & 180.38 & 104.07 & 0.91 & 0.11 & -0.79 \\
\hline & Tal & 119.04 & 85.27 & 26.98 & -0.48 & $-2.14^{\mathrm{a}}$ & $-1.66^{a}$ \\
\hline & Kes & 60.63 & 84.66 & 24.67 & 0.48 & $-1.30^{\mathrm{a}}$ & $-1.78^{\mathrm{a}}$ \\
\hline & Hep & 0.80 & 0.29 & 0.18 & $-1.47^{\mathrm{a}}$ & $-2.19^{\mathrm{a}}$ & -0.72 \\
\hline & mlno & 11.07 & 24.44 & 4.62 & $1.14^{\mathrm{a}}$ & $-1.26^{\mathrm{a}}$ & $-2.40^{\mathrm{a}}$ \\
\hline & Sor & 9.78 & 3.13 & 3.42 & $-1.65^{a}$ & $-1.52^{\mathrm{a}}$ & 0.13 \\
\hline & Rib & 9.02 & 5.24 & 1.56 & -0.78 & $-2.53^{\mathrm{a}}$ & $-1.75^{\mathrm{a}}$ \\
\hline & Gala & 0.85 & 3.22 & 0.84 & $1.92^{\mathrm{a}}$ & -0.02 & $-1.94^{\mathrm{a}}$ \\
\hline & Raf & 0.39 & 1.01 & 0.10 & $1.39^{\mathrm{a}}$ & $-1.91^{\mathrm{a}}$ & $-3.29^{\mathrm{a}}$ \\
\hline
\end{tabular}

The relative concentration of each metabolite is an average of data from six biological replicates obtained through GC-MS. Fold changes were calculated using 
of high amounts of phosphate and metal ion precipitate, except $\mathrm{Na}$ and $\mathrm{K}$; as a consequence, ionic activities and free concentrations of various ions decreased. Salt stress reduced $\mathrm{Ca}$ accumulation in wheat roots; by contrast, alkali stress strongly induced $\mathrm{Ca}$ accumulation in roots. Under alkali stress, increasing $\mathrm{Ca}$ concentration can immediately trigger SOS1 Na exclusion system and reduce $\mathrm{Na}$ injury. We detected the 75 metabolites that were different among the treatments, including organic acids, amino acids, and carbohydrates. A dynamic trajectory was observed in wheat metabolic profiles in response to salt and alkali stress. Based on the comparison results of metabolic profiles and SPAD values between salt stress and alkali stress, the harmful effects of alkali stress on the distribution and accumulation of metabolites were significantly greater than those of salt stress; these outcomes correspond to specific detrimental effects of a highly alkaline environment. Prolonged salt stress induced progressive accumulation of sugars by gluconeogenesis to avoid osmotic stress. Such treatment also promoted energy metabolism in roots and active synthesis in leaves to develop salt tolerance in wheat. Alkali stress (at high $\mathrm{pH}$ ) significantly inhibited photosynthetic rate; thus, sugar production was reduced, $\mathrm{N}$ metabolism was limited, amino acid production was reduced, and glycolysis was inhibited. Alkali stress also severely inhibited nitrate uptake by roots and subsequent $\mathrm{N}$ assimilation, possibly decreasing the accumulation of amino acids. Therefore, energy and high organic acid concentrations are possible key adaptive factors needed by wheat to maintain intracellular ion balance and regulate high $\mathrm{pH}$ under alkali stress.

\section{Additional files}

Additional file 1: Relative concentration and fold changes of 75 metabolites in leaves of wheat seedlings after 15 days of salt and alkali treatment. The relative concentration of each metabolite is an average of data from five biological replicates using GC-MS. The fold changes was calculated using the formula $\log _{2}^{(\text {treatment/control) }}$. *indicate significant $(P<0.05)$.

Additional file 2: Relative concentration and fold changes of 75 metabolites in roots of wheat seedlings after 15 days of salt and alkali treatment. The relative concentration of each metabolite is an average of data from five biological replicates using GC-MS. The fold changes was calculated using the formula $\log _{2}^{\text {(treatment/control). }}$ *indicate significant $(P<0.05)$.

\section{Abbreviations}

Cit: Citric acid; Aco: Aconitic Acid; a-KG: a-ketoglutaric acid; Succ: Succinic acid; Fum: Fumaric acid; Mal: Malic acid; Glc: Glucose; G6P: Glucose-6-phosphate; F6P: Fructose-6-phosphate; 3-PGA: 3-phosphoglycerate; Pyr: Pyruvate; PEP: Phosphoenolpyruvate; Glu: Glutamate; GABA: $\gamma$-aminobutyric acid; Ala: Alanine; Asp: Aspartic acid; Gly: Glycine; Thr: Threonine; Ser: Serine; Val: Valine; Pro: Proline; Phe: Phenylalanine; Gln: Glutamine; Ile: Isoleucine; Leu: Leucine; Asn: Asparagine; Fru: Fructose; Suc: Sucrose; Tal: Talose; Kes: Kestose; Hep: Heptulose; mlno: myo-Inositol; Sor: Sorbitol; Rib: Ribose; Gala: Galactinol; Raf: Raffinose.

\section{Competing interests}

The authors declare that they have no competing interests.

\section{Authors' contributions}

$R G$ and $Z Y$ designed the study. RG, $X Z, Q L$, and $X X$ performed the experiments. $R G, L H, C Y$ and $L Z$ analyzed the data. $R G$ wrote the manuscript. All authors read and approved the final manuscript.

\section{Acknowledgments}

This research was supported by grants from the Project of the National Natural Science Foundation of China (No. 31200243, 31170303, 31270366), and the National High-Tech R \& D Program (863 Program) for the $12^{\text {th }}$ Five-Year Plan (2011AA100503), and the basic research special fund operations (No. BSRF201201), and National "Twelfth Five-Year" Plan for Science \& Technology Support (2011BAD09B01). We thank the two anonymous reviewers for the critical and constructive comments for further improving of the manuscript. We are also grateful to Mr. Junliang Deng (Biotree Bio-technology Co., Ltd., Shanghai, China) for providing helps in data measure and analysis.

\section{Author details}

'Institute of Environment and Sustainable Development in Agriculture (IEDA), Chinese Academy of Agricultural Sciences (CAAS)/Key Laboratory of Dryland Agriculture, Ministry of Agriculture, Beijing 100081, P.R. China. ${ }^{2}$ Key laboratory of Molecular Epigenetics of Ministry of Education (MOE), Northeast Normal University, Changchun 130024, China.

Received: 11 May 2015 Accepted: 10 June 2015

Published online: 07 July 2015

\section{References}

1. Munns R, Tester M. Mechanisms of salinity tolerance. Annu Rev Plant Biol. 2008:59:651-81.

2. FAO: FAO land and plant nutrition management service. http://www.fao.org/ ag/agl/agll/spush. 2009

3. Läuchli A, Lüttge U. Salinity: environment - plants - molecules. Springer. 2002;552.

4. Lu YH, Lam HM, Pi EX, Zhan QL, Tsai S, Wang CM, et al. Comparative metabolomics in glycine max and glycine soja under salt stress to reveal the phenotypes of their off spring. J Agric Food Chem. 2013;61:8711-21.

5. Wu DZ, Shen QF, Cai SG, Chen ZH, Dai F, Zhang GP. lonomic responses and correlations between elements and metabolites under salt stress in wild and cultivated barley. Plant Cell Physiol. 2013;0(0):1-13. doi:10.1093/pcp/ pct134.

6. Nuttall JG, Armstrong RD, Connor DJ. Evaluating physicochemical constraints of Calcarosols on wheat yield in the Victorian southern Mallee. Aust J Agric Res. 2003;54:487-97.

7. Hartung W, Leport L, Ratcliffe RG, Sauter A, Duda R, Turner NC. Abscisic acid concentration, root $\mathrm{pH}$ and anatomy do not explain growth differences of chickpea (Cicer arietinum L.) and lupin (Lupinus angustifolius L.) on acid and alkaline soils. Plant Soil. 2002;240:191-9.

8. Campbell SA, Nishio JN. Iron deficiency studies of sugar beet using an improved sodium bicarbonate-buffered hydroponic growth system. J Plant Nutr. 2000;23:741-57.

9. Ghoulam C, Foursy A, Fares K. Effects of salt stress on growth, inorganic ions and proline accumulation in relation to osmotic adjustment in five sugar et cultivars. Environ Exp Bot. 2002;47:39-50.

10. De-Lacerda CF, Cambraia J, Oliva MA, Ruiz HA, Prisco JT. Solute accumulation and distribution during shoot and leaf development in two sorghum genotypes under salt stress. Environ Exp Bot. 2003;49:107-20.

11. Munns R. Comparative physiology of salt and water stress. Plant Cell Environ. 2002;25:239-50.

12. Yang $C, X u H H$, Wang L, Liu J, Shi DC, Wang D. Comparative effects of salt-stress and alkaline-stress on the growth, photosynthesis, solute accumulation, and ion balance of barley plants. Photosynthetica. 2009;47(1):79-86.

13. Yang C, Chong J, Kim C, Li C, Shi D, Wang D. Osmotic adjustment and ion balance traits of an alkaline resistant halophyte Kochia sieversiana during adaptation to saline and alkaline conditions. Plant Soil. 2007;294:263-76. 
14. Xue YF, Liu ZP. Effects of $\mathrm{NaCl}$ and $\mathrm{Na}_{2} \mathrm{CO}_{3}$ stresses on photosynthesis and parameters of chlorophyll fluorescence in Helianthus Tuberosus seedlings. J Plant Ecol. 2008;32(1):161-7.

15. Guo R, Shi LX, Yang YF. Germination, growth, osmotic adjustment and ionic balance of wheat in response to saline and alkaline stresses. Soil Sci Plant Nutr. 2009:55:667-79.

16. Bino RJ, Hall RD, Fiehn O, Kopka J, Saito K, Draper J, et al. Potential of metabolomics as a functional genomics tool. Trends Plant Sci. 2004:9:418-25.

17. Shulaev V, Cortes D, Miller G, Mittler R. Metabolomics for plant stress response. Physiol Plantarum. 2008;132:199-208.

18. Meng JR, Zhang XD, Wu H, Bu J, Shi CY, Deng CH, et al. Morphine-induced conditioned place preference in mice: Metabolomic profiling of brain tissue to find "molecular switch" of drug abuse by gas chromatography/mass spectrometry. Anal Chim Acta. 2011;710:125-30.

19. Ruan CJ, Silva JAT. Metabolomics: Creating new potentials for unraveling the mechanisms in response to salt and drought stress and for the biotechnological improvement of xero-halophytes. Crit Rev Biotechno. 2011;31(2):153-69.

20. Barding GA, Béni S, Fukao T, Bailey-Serres J, Larive CK. Comparison of GC-MS and NMR for Metabolite Profiling of Rice Subjected to Submergence Stress. J Proteome Res. 2013;12(2):898-909.

21. Dai H, Xiao CN, Liu HB, Tang HR. Combined NMR and LC-MS Analysis Reveals the Metabonomic Changes in Salvia miltiorrhiza Bunge Induced by Water Depletion. J Proteome Res. 2010;9:1460-75.

22. Kingsbury RW, Epstein E, Pearcy RW. Physiological responses to salinity in selected lines of wheat. Plant Physiology. 1984;74:417-23.

23. Arnon DI. Copper enzymes in isolated chlorop lasts phenoloxidases in Beta Vulgaris. Plant Physiol. 1949;24:1-15.

24. Zhu JK. Regulation of ion homeostasis under salt stress. Curr Opin Plant Biol. 2003:6:441-5.

25. Lisec J, Schauer N, Kopka J, Willmitzer L, Fernie AR. Gas chromatography mass spectrometry-based metabolite profiling in plants. Nat Protoc. 2006;1:387-96

26. Kind T, Wohlgemuth G, Lee Do Y, Lu Y, Palazoglu M, Shahbaz S, et al. FiehnLib: mass spectral and retention index libraries for metabolomics based on quadrupole and time-of-flight gas chromatography/mass spectrometry. Anal Chem. 2009;81(24):10038-48.

27. Dunn WB, Broadhurst D, Begley P, Elena E, Francis-Mcintyre S, Anderson N. Procedures for large-scale metabolic profiling of serum and plasma using gas chromatography and liquid chromatography coupled to mass spectrometry. Nat Protocols. 2011;6(7):1060-83.

28. Xia J, Mandal R, Sinelnikov I, Broadhurst D, Wishart DS. MetaboAnalyst 2.0 a comprehensive server for metabolomic data analysis. Nucl Acids Res. 2012;40:127-33.

29. Paz H, Martinez-Ramos M. Seed mass and seedling performance within eight species of Psychotria (Rubiaceae). Ecol. 2003;84:439-50.

30. Yang C, Jianaer A, Li C, Shi C, Wang D. Comparison of the effects of salt-stress and alkaline-stress on photosynthesis and energy storage of an alkali-resistant halophyte Chloris virgata. Photosynthetica. 2008:46:273-8.

31. Bethke PC, Drew MC. Stomatal and non-stomatal components to inhibition of photosynthesis in leaves of Capsicum annuum during progressive exposure to $\mathrm{NaCl}$ salinity. Plant Physiol. 1992;99:219-26.

32. Shi DC, Zhao KF. Effects of $\mathrm{NaCl}$ and $\mathrm{Na}_{2} \mathrm{CO}_{3}$ on growth of Puccinellia tenuiflora and on present state of mineral elements in nutrient solution. Acta pratacu. 1997:6:51-61.

33. Guo R, Shi LX, Ding XM, Hu YJ, Tian SY. Effects of saline and alkaline stress on germination, seedling growth and ion balance in wheat. Agronomy J. 2010;102(4):1252-60.

34. Guo R, Zhou J, Ren GX, Hao WP. Physiological responses of linseed seedlings to iso-osmotic polyethylene glycol, salt, and alkali stresses. Agronomy J. 2013;105(3):764-72.

35. Dodd K, Guppy C, Lockwood P, Rochester I. The effect of sodicity on cotton: Plant response to solutions containing high sodium concentrations. Plant Soil. 2010;330:239-49.

36. Yang C, Zhao N, Xu C, Liu B, Shi D. Regulation of ion homeostasis in rice subjected to salt and alkali stresses. Austr J Crop Sci. 2012;6(4):724-31.

37. Zhang JT, Zhang Y, Du YY, Chen SY, Tang HR. Dynamic metabonomic responses of tobacco (Nicotiana tabacum) plants to salt stress. J Proteome Res. 2011;10:1904-14

38. Hare PD, Cress WA. Metabolic implications of stressinduced proline accumulation in plants. Plant Growth Regul. 1997;21:79-102.
39. Hare PD, Cress WA, Staden JV. Dissecting the roles of osmolyte accumulation during stress. Plant Cell Environ. 1998;21:535-53.

40. Wang H, Ahan J, Wu ZH, Shi DC, Liu B, Yang CW. Alteration of nitrogen metabolism in rice variety 'Nipponbare' induced by alkali stress. Plant Soil. 2012;355:131-47

41. Crawford NM, Glass ADM. Molecular and physiological aspects of nitrate uptake in plants. Trends Plant Sci. 1998:3:389-95.

\section{Submit your next manuscript to BioMed Central and take full advantage of:}

- Convenient online submission

- Thorough peer review

- No space constraints or color figure charges

- Immediate publication on acceptance

- Inclusion in PubMed, CAS, Scopus and Google Scholar

- Research which is freely available for redistribution 